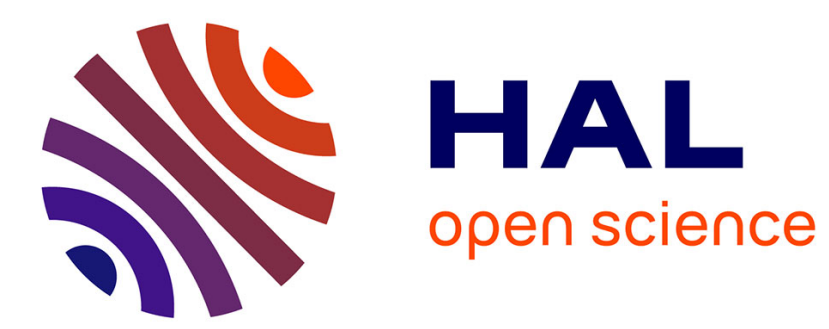

\title{
Current Status of Soft Ferrite in Japan
}

\author{
T. Ohiai
}

\section{- To cite this version:}

T. Ohiai. Current Status of Soft Ferrite in Japan. Journal de Physique IV Proceedings, 1997, 07 (C1), pp.C1-27-C1-30. 10.1051/jp4:1997102 . jpa-00254712

\section{HAL Id: jpa-00254712 https://hal.science/jpa-00254712}

Submitted on 1 Jan 1997

HAL is a multi-disciplinary open access archive for the deposit and dissemination of scientific research documents, whether they are published or not. The documents may come from teaching and research institutions in France or abroad, or from public or private research centers.
L'archive ouverte pluridisciplinaire HAL, est destinée au dépôt et à la diffusion de documents scientifiques de niveau recherche, publiés ou non, émanant des établissements d'enseignement et de recherche français ou étrangers, des laboratoires publics ou privés. 


\title{
Current Status of Soft Ferrite in Japan
}

\author{
T. Ohiai
}

Materials Research Center, TDK Corporation, 570-2, Aza-matugasita, Minamihatori, Narita-shi, Chiba 286, Japan

\begin{abstract}
This paper focuses on recent developments in the field of materials technology of soft ferrites in Japan. With the rapid development of the electronics market, the ferrite industry has grown to a considerable size. Magnetic characteristics of ferrites are quite sensitive to the chemical composition, the production process and to microstructure. Controlling these factors is an important key to achieving high performance ferrites. MnZn ferrites are classified according to their characteristics. High initial permeability materials are used for wide band and pulse transformers, and low power loss materials are used for power application. High initial permeability, over 20000 at $10 \mathrm{kHz}$, was achieved by $\mathrm{Bi}_{2} \mathrm{O}_{3}$ addition using high purity raw materials. Low loss $\mathrm{MnZn}$ ferrite, with $\mathrm{Pcv}=199 \mathrm{~kW} / \mathrm{m}^{3}$ at $100 \mathrm{kHz}$, has recently been developed by $\mathrm{SnO}_{2}$ addition under some optimized process conditions. NiClen ferrite is employéd for multilayer-ferrite chip-components(MLFC). Low oxygen partial pressure during sintering is an important factor in controlling the nanostructure of grain boundaries. MnMgZn ferrite has been produced in large quantity for deflection yoke application because of its high cost performance. Investigation of composition, additives and sintering conditions has made it possible to obtain lower loss than that in NiCuZn ferrite measured at higher temperatures.
\end{abstract}

\section{INTRODUCTION}

Since the discovery of an efficient mixedferrite by Dr. Yogoro Kato and Dr. Takesi Takei about 60 years ago [1], much basic and applied research and development has been carried out in Europe as well as in Japan. In the 1940's and 1950's, ferrites were systematized in the academic field and today ferrite theory is well organized In 1935, Japan pioneered the mass-production of ferrites. From the 1950's, as radio and television sets spread, ferrites established a significant position in industry, and now ferrites are one of the most essential materials in the electronics industry.

Soft ferrites are widely used in electronic devices as magnetic cores for high frequency applications. The advantages of ferrites for these applications are higher electronic resistivity as opposed to metals, high machinability, ease of de pressing, chemical stability and lower cost. Figure. 1 shows the average monthly sales of soft magnetic ferrite cores in Japan in the last seven years, which were taken from the Electronic Materials Manufacture's Association of Japan. The sales for the year of 1991 declined slightly on account of the business recession over the world. However, after that, the ferrite business has been improved stably. Sales of soft ferrites, shown in Fig. 1, have been classified by fields of application in Fig.2. In spite of a recent stability in the overall market, the sales in deflection yoke and power applications have grown gradually. The former has been supported by sales of CRTs(Cathode Ray Tube) for personal computer and television sets for home use, while the latter is due to switching power supply.

Various pefformance characteristics of ferrites are necessary for varied applications. However, basically high permeability, high saturation magnetization, high Curie temperature, andlow loss are expected. It is impossible for one type of ferrite to possess all of these at once, and the type of ferrite should be chosen depending on what performancecharacteristicis important. In the following sections, the review of recent developments in the field of materials technology of soft ferrites is described. 


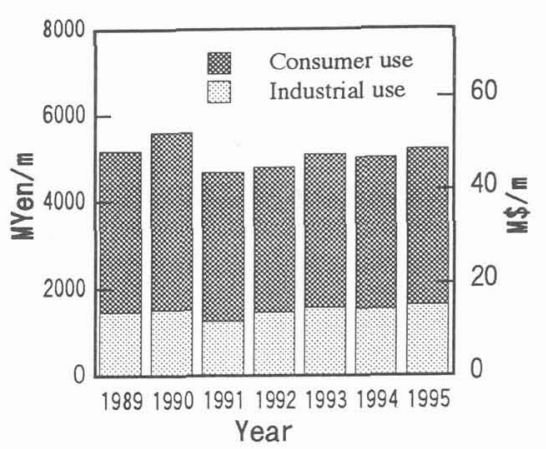

Fig. 1 Average monthly sales of soft ferrite in Japan.

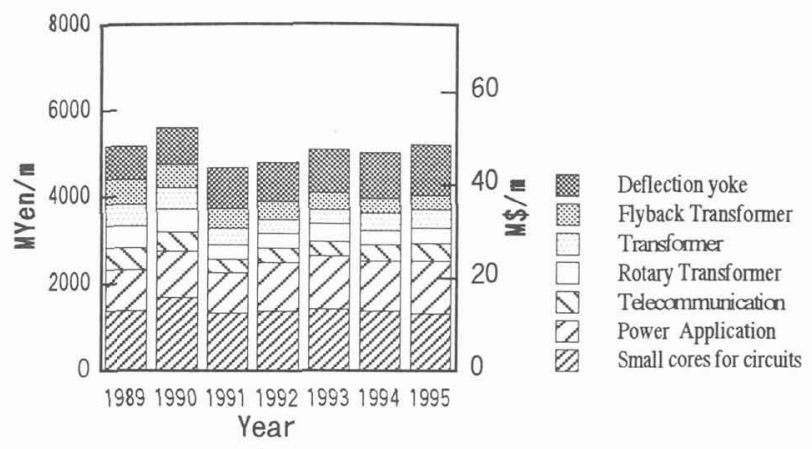

Fig.2 Sales of soft ferrite classified by fields of application.

\section{High initial permeability $M n Z n$ ferrite}

High initial permeability $\mathrm{MnZn}$ ferrites are mainly used in devices for telecommunication applications such as the pulse transformer. For high initial permeability, some technological innovations have been applied [2-5]. One is compositional choice for small magnetocrystalline anisotropy constant and magnetostrictive constant. The other is high mobility of domain wall by inducing low residual stress and controlling microstructure, grain size, and defects.

The temperature dependence of initial permeability of $\mathrm{Bi}_{2} \mathrm{O}_{3}$ added specimens are shown in Fig.3. High permeability $\mathrm{MnZn}$ ferrites, with $\mu_{i}=23000$ and $\tan \delta / \mu_{i}=10 \times 10^{-6}$ at $10 \mathrm{kHz}$, have been developed by optimization of compositions and sintering process conditions. Grain growth is thought to result from $\mathrm{Bi}_{2} \mathrm{O}_{3}$ addition to $\mathrm{MnZn}$ ferrite [6]. However, the experimental results are substantially different [7]. Thus, the high permeability should be explained by an effect other than $\mathrm{Bi}_{2} \mathrm{O}_{3}$ addition. The compositional distributions near grain boundaries are shown in Fig.4. The Bismuth content dependence on the $\delta$ value is shown in Fig.5, representing oxygen content in the sintered body. Smaller $\delta$ value deviations were obtained for $\mathrm{Bi}_{2} \mathrm{O}_{3}$ added specimens rather than those of specimens without $\mathrm{Bi}_{2} \mathrm{O}_{3}$. It is assumed that $\mathrm{Bi}$ promotes diffusion mobility of $\mathrm{O}_{2}$ through grain boundaries. High initial permeability is therefore thought to be due to the homogeneous oxygen content dstribution in the sintered body, facilitated by high diffusion mobility.

\section{Low power-loss $\mathrm{MnZn}$ ferrite}

Low power-loss $\mathrm{MnZn}$ ferrite is widely used for power application such as the switched-mode power converter. Power loss is theoretically dvided into hysteresis, edty current, and residual losses $[8]$. These three functions are distinguished from each other according to the difference in their frequency dependencies. Eddy current loss is proportional to the reciprocal of electrical resistivity. High electrical resistivity is one of the most important characteristics for the power ferrite. This characteristic has been improved mainly by adequate additives [9] . It is well known that the addition of $\mathrm{CaO}$ and $\mathrm{SiO}_{2}$ in $\mathrm{Mn} \mathrm{Zn}$ ferrite is effective in raising the electrical resistivity through the formation of an insulating layer along the grain boundaries. In order to achieve lower loss characteristics, high resistivity in the main phase has been required.

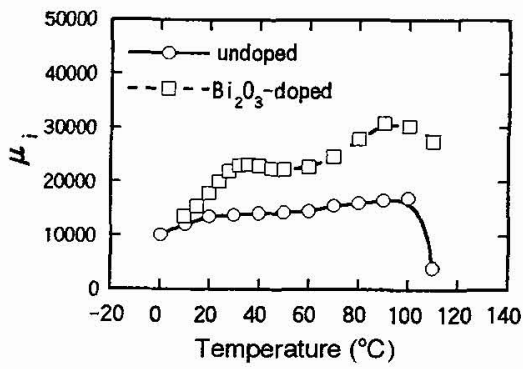

Fig. 3 Temperature dependence of initial permeability of $\mathrm{Bi}_{2} \mathrm{O}_{3}$ added high $\mu_{i} \mathrm{MnZn}$ ferrites.

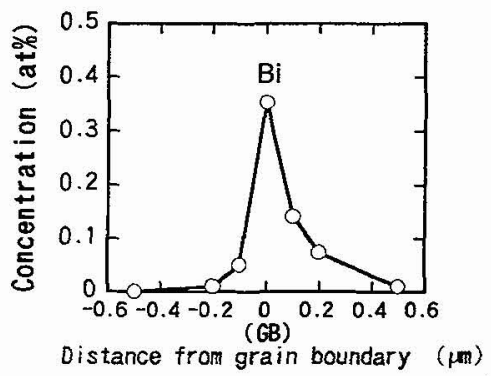

Fig. 4 Distribution near grain boundaries of $\mathrm{Bi}_{2} \mathrm{O}_{3}$ of $\mathrm{MnZn}$ ferrite samples.

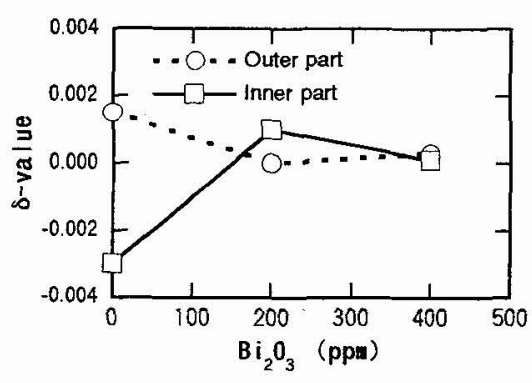

Fig. 5 Effect of $\mathrm{Bi}_{2} \mathrm{O}_{3}$ doping on the $\delta$-value. 


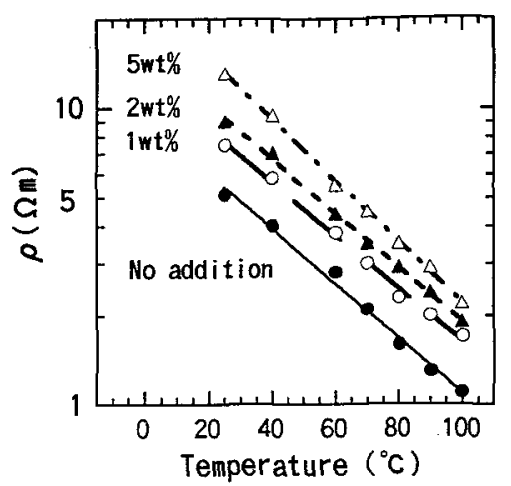

Fig. 6 Temperature dependence of dc resistivity as a function of $\mathrm{SnO}_{2}$.

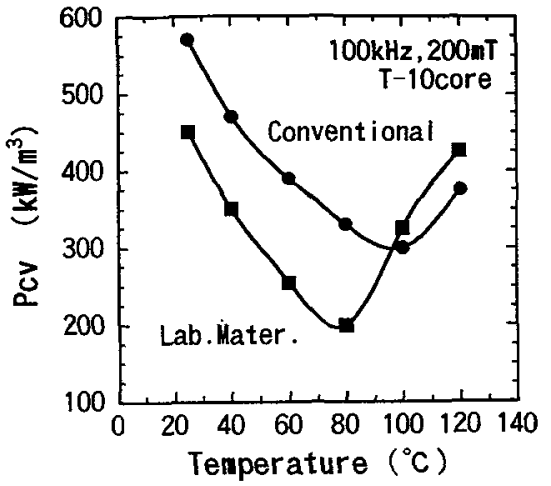

Fig. 7 Temperature dependence of power loss of $M n Z n$ ferrite.

$\mathrm{SnO}_{2}$ is well known to be soluble in spinel [10] and to compensate for $\mathrm{Fe}^{2+}$. Figure. 6 shows the temperature dependence of dc resistivity as a function of $\mathrm{SnO}_{2}$ content. Addition of $\mathrm{SnO}_{2}$ to $\mathrm{MnZn}$ ferrite was effective in controlling the electron transfer between $\mathrm{Fe}^{2+}$ and $\mathrm{Fe}^{3+}$, and consequently increased the resistivity. As a result, low loss $\mathrm{MnZn}$ ferrite, $\mathrm{Pcv}=199 \mathrm{~kW} / \mathrm{m}^{3}(100 \mathrm{kHz}, 200 \mathrm{mT}$, $80^{\circ} \mathrm{C}$ ), has been recently developed by $\mathrm{SnO}_{2}$ addition under some selected process conditions, as is shown in Fig.7 [11] .

\section{NiCuZn ferrite}

$\mathrm{NiCuZn}$ ferrite is employed for multilayer-ferrite chipcomponents (MLFC), because of $i$ ts high performance at high frequencies. The sintering temperature of $\mathrm{NiCuZn}$ ferrite for MLFC should be below $900^{\circ} \mathrm{C}$ to avoid melting the internal Ag winding. Nakano, et. al. $[12,13]$ reported that $\mathrm{Ag}$ introduced a compressive residual stress by diffusing into the ferrite, which was observed as interference fringes at grain boundaries by TEM. Recently, in order to achieve high frequency and high performance MLFC, other additives have been studied [14]. Figure.8illustrates the effectof impurities on the Q-factor of a chip inductor. Adkition of $\mathrm{COO}$ was effective in improving the $\mathrm{Q}$-factor to a maximum amount of 2000-3000 ppm, while other impurities degraded it. Sintering conditions are also an important factor. High purity of raw materials for $\mathrm{NiCuZn}$ ferrite are essential to MLFC. The effect of oxygen partial pressure during sintering on dc resistivity is shown in Fig.9. Low oxygen partial pressure, such as 5\% oxygen, led to high dc resistivity and high Q-factor because of the decreasing residual stress (manifested as a reduction in interference fringes).

Production of multilayer-ferrite chip-components has grown remarkably in past years. To enhance the performance of MLFC, it is of prime importance to control the small amount of ingredients and the firing conditions, as well as to control the stress caused by internal $\mathrm{Ag}$ winding. New progress in MLFC can be expected using such material technology.

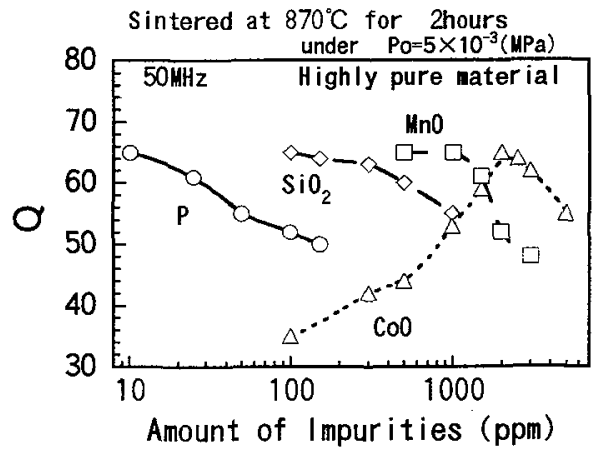

Fig.8 Effect of impurities on the Q-factor of chip inductor.

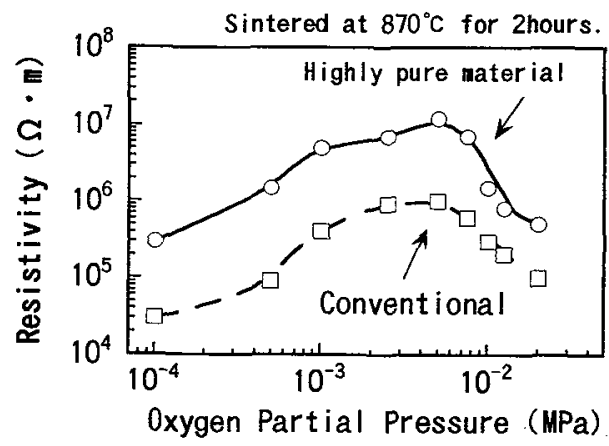

Fig.9 Effect of $\mathrm{PO}_{2}$ on the de resistivity of $\mathrm{NiCuZn}$ ferrite. 


\section{5. $M n M g Z n$ ferrite}

MnMgZn ferrites have been produced in large quantity for deflection yoke application because of its high cost performance. Recently, wider screen and high definition television for home use and high definition PC dsplay have been in high demand Higher performance of ferrite materials for deflection yokes are necessary to match such demand. High saturation magnetization and low loss, as well as small shape tolerance, are important properties forferrites for deflection yokes [15] . In Fig.10, the temperature dependence of power loss of low loss MnMgZn ferrite is shown [16] . Investigation of composition, additives and sintering condtions have made it possible to obtain lower loss than that in NiCuZnferrite at higher temperatures. Smaller magnetocrystalline anisotropy achieved by optimizing the oxidation grade of metal ions [17], andhigher resistivity of the grain and grain boundaries, by the control of microstructure, are thought to be the main factors yielding low loss.

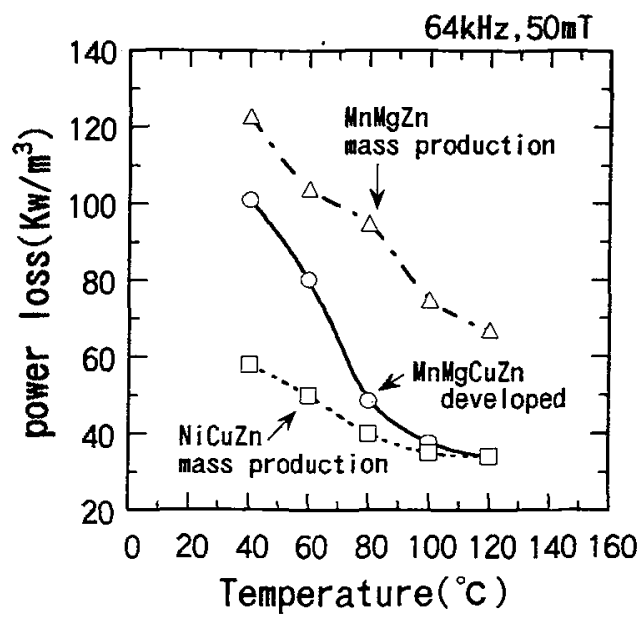

Fig. 10 Temperature dependence of power loss of $\mathrm{MnMgZn}$ ferrite.

\section{CONCLUDING REMARKS}

There is no doubt that the ferrites market will grow steadily as magnetic materials for high frequency devices. No alternative materials are projected for the future. In adkition, higher electronic and magnetic properties for ferrites have been demanded corresponding to the electronic industry pursuing smaller and higher performance electronic devices. For high performance ferrites, control of microstructures as well as grain boundaries is necessary. Among the many ferrite production process factors, purity of raw materials, additives and sintering process should be well optimized. As the latest process for ferrites production, the co-spray roasting method has been industrialized. High purity ferrites are obtained from relativelylow cost raw materials with high impurity content through this excellent process. And more advanced technology for structural analysis, definitive composition analysis and performance evaluation at high frequency are essential for the next generation of ferrites.

After the passing of sixty years of ferrite history, it is generally believed that the growth stage had finished and that the maturity stage has started. However, new applications of ferrites, such as toners and ferrite carrierfor photocopy machines and the application of biotechnology, have been developing. I believe that much high performance and high dependability of ferrites will be achieved through new materials process and microstructure control technology based on our exciting technology and theory.

\section{Reference}

[1] Y.Kato and T.Takei, Japan Patent, 98844 (1932)

[2] Y.Shichijo, Trans.Jap_nst.Metals, 2 (1961) 204.

[3] K.Ohta and N.Kobayashi, Jpn.J.Appl.Phys., 3 (1964) 576.

[4] A.Beer and J.Schwartz, IEEE Trans.Magn., MAG -2 (1966) 470.

[5] D.J.Perduijin and H.P.Peloschek, Proc.Brit.Cer.Soc., 10 (1968) 268.

[6] P.D.Baba, G.M.Argentina, W.E.Countney, G.F.Dionne and D.H.Temme, IEEE Trans.Magan., MAG-8 (1972) 83.

[7] K.Horino andT.Nomura, "High initial permeability MnZn ferrite”, Proc. of 15th Takei Seminar, Nagano Pref. Japan, 14-15 July 1995, pp.1-9

[8] K.Ohta, Basic of magnetism engineering vol. II, (Kyouritu,Tokyo Japan, 1973) pp.309

[9] T.Akashi, Trans_Jpn.Inst.Metals, 2 (1961) 171.

[10] J.E.Knowles, Philips Res. Repts., 29 (1974) 93.

[11] T.Minakawa, N.Sato, and T.Nomura, J.Magn.Soc.Jpn., 20 (1996) 497.

[12] A.Nakano, H.Momoi, and T.Nomura, J.Jpn.Soc.Powder and Powder Met., 39 (1992) 612.

[13] A.Nakano, H.Momoi, and T.Nomura, Proc. 6th Intnl.Conf.Ferrites, (1992) 1225.

[14] T.Suzuki and T.Nommura, J.Soc.Mater.Eng.Resour.Jpn., 6 (1993) 51.

[15] S.Hiraga, K.Okutani, and T.Ojima, Ferrite (Maruzen, Tokyo Japan, 1986) pp.118

[16] T.Murase, K.Igarashi, T.Yamazaki, T.Nomura, and T.Ochiai, J.Magn.Soc.Jpn., 19 (1995) 413.

[17] A.Brose et al., Mater.Sci.Eng., 3 (1968/69) 341. 